\title{
Trichostatin A Promotes the Generation and Suppressive Functions of Regulatory T Cells
}

\author{
Cristian Doñas, ${ }^{1,2}$ Macarena Fritz, ${ }^{1,2}$ Valeria Manríquez, ${ }^{3}$ Gabriela Tejón, ${ }^{3}$ \\ María Rosa Bono, ${ }^{3}$ Alejandra Loyola, ${ }^{2,4}$ and Mario Rosemblatt ${ }^{1,2,3}$ \\ ${ }^{1}$ Departamento de Ciencias Biológicas, Universidad Andrés Bello, República 275, Santiago, Chile \\ ${ }^{2}$ Fundación Ciencia \& Vida, Avenida Zañartu 1482, Ñunoa, Santiago, Chile \\ ${ }^{3}$ Laboratorio de Inmunología, Departamento de Biología, Facultad de Ciencias, Las Palmeras 3425, Ñunoa, \\ Universidad de Chile, Santiago, Chile \\ ${ }^{4}$ Universidad San Sebastián, Avenida Lota 2465, Providencia, Santiago, Chile
}

Correspondence should be addressed to Mario Rosemblatt; mrosemblatt@cienciavida.cl

Received 30 January 2013; Revised 9 April 2013; Accepted 9 April 2013

Academic Editor: Nicolaus Kroger

Copyright (C) 2013 Cristian Doñas et al. This is an open access article distributed under the Creative Commons Attribution License, which permits unrestricted use, distribution, and reproduction in any medium, provided the original work is properly cited.

Regulatory T cells are a specific subset of lymphocytes that suppress immune responses and play a crucial role in the maintenance of self-tolerance. They can be generated in the thymus as well as in the periphery through differentiation of naïve CD $4^{+} \mathrm{T}$ cells. The forkhead box P3 transcription factor (Foxp3) is a crucial molecule regulating the generation and function of Tregs. Here we show that the foxp 3 gene promoter becomes hyperacetylated in in vitro differentiated Tregs compared to naïve $\mathrm{CD} 4^{+} \mathrm{T}$ cells. We also show that the histone deacetylase inhibitor TSA stimulated the in vitro differentiation of naïve CD $4^{+} \mathrm{T}$ cells into Tregs and that this induction was accompanied by a global increase in histone $\mathrm{H} 3$ acetylation. Importantly, we also demonstrated that Tregs generated in the presence of TSA have phenotypical and functional differences from the Tregs generated in the absence of TSA. Thus, TSA-generated Tregs showed increased suppressive activities, which could potentially be explained by a mechanism involving the ectonucleotidases CD39 and CD73. Our data show that TSA could potentially be used to enhance the differentiation and suppressive function of $\mathrm{CD}^{+}$Foxp $^{+}$Treg cells.

\section{Introduction}

Regulatory T cells (Treg) are a specific subset of lymphocytes that suppress immune responses and play a crucial role in the maintenance of self-tolerance $[1,2]$. Their development and function are programmed by the forkhead box P3 transcription factor Foxp3, which is predominantly expressed in $\mathrm{CD} 4^{+} \mathrm{CD} 25^{+}$Treg cells $[1,3]$. Tregs actively suppress the activation and expansion of autoreactive immune cells to limit the duration and extent of inflammation. Therefore, a decrease in Treg activity can contribute to autoimmunity and inflammatory diseases [4]. Because of their suppressive capacities, Tregs represent a promising strategy for inducing tolerance to self- and non-self-antigens in such diseases.

In recent years, increasing evidence has demonstrated the role of epigenetic alterations in the etiology of many autoimmune and inflammatory diseases through changes in DNA methylation and histone modifications $[5,6]$. Therefore, it is important to determine crucial histone modifications for Treg development and function and to study compounds able to revert or modify epigenetic patterns.

Among histones modifications is acetylation, which occurs at lysine residues mainly on their amino-terminal tails. This posttranslational modification is dynamic and its overall effect on gene expression depends on the balance between histone acetyltransferases (HATs) and histone deacetylases (HDACs) $[7,8]$. HDACs typically dampen histone-DNA and histone-non histone protein interactions $[9,10]$, but they also regulate the function of non-histone proteins [11].

Histone deacetylase inhibitors (HDACi) such as trichostatin A (TSA) are small molecule compounds capable of inhibiting class I, II, and IV HDAC families of enzymes [12]. 
Previous studies in mice have shown that TSA administration in vivo promotes the generation and function of Tregs [13], and has beneficial effects in cardiac allograft transplant, inflammatory bowel disease [13] and lupus models [14]. Unfortunately, none of these studies provided in vitro data regarding the effect of TSA on Treg generation from conventional $\mathrm{CD} 4^{+} \mathrm{CD} 25^{-} \mathrm{T}$ cells and their suppressive function, making it difficult to understand whether these are direct or indirect effects. Our study provides evidence that TSA increases the generation of $\mathrm{CD} 4^{+}$Foxp $3^{+}$Tregs in vitro and gains insight into the regulation of $\mathrm{CD} 4^{+} \mathrm{Foxp}^{+}$Tregs by the deacetylase inhibitor TSA.

\section{Materials and Methods}

2.1. Animals. Six- to eight-week-old Foxp3-GFP mice were used for all experiments. All mice were maintained and manipulated according to institutional guidelines at the pathogen-free facility of Fundación Ciencia \& Vida after approval by the Ethical Review Committee.

2.2. Antibodies. Anti-CD3e, anti-CD16/32, anti-CD4$\mathrm{APCH}$, anti-CD25-APC, anti-IL-17A-PE, anti-IFN $\gamma$-PECy7, and anti-CD39-PE, anti-GARP-PE, anti-CD73-Cy7 were purchased from eBioscience (CA, USA). Anti-CTLA-4-PE was purchased from BD PharMingen (NJ, USA). Anti-IL10-PE, anti-LAG3-biotin, streptavidin-APC, anti-IL4, and anti-IFN $\gamma$ were purchased from BioLegend (CA, USA). Anti-H3ac and anti-H3 were purchased from Abcam (MA, USA) and Rabbit IgG from Millipore (MA, USA).

2.3. Flow Cytometry and Cytokine Secretion Analysis. The expression of cell surface markers on $\mathrm{T}$ cells was determined by FACS analysis after surface staining with specific antimouse antibodies. To determine IL-10 secretion, Treg cells were stimulated for $4 \mathrm{~h}$ at $37^{\circ} \mathrm{C}$ with $50 \mathrm{ng} / \mathrm{mL}$ PMA and $1 \mathrm{ug} / \mathrm{mL}$ ionomycin (Sigma-Aldrich). Following the reactivation, the supernatants were recovered and immediately analyzed using a mouse BD cytometric assay array (CBA). All data were collected on a FACSCanto II (BD Biosciences) and analyzed with FACS Diva software (BD, New Jersey) or FlowJo software (TreeStar).

\subsection{Purification of $T$ Cells and In Vitro $T$ Cell Differenti-} ation. Splenic $\mathrm{CD}^{+} \mathrm{T}$ cells from Foxp3-GFP mice were enriched by MACS purification using the CD4 isolation kit II (Miltenyi Biotec) following the manufacturer's instructions. Naive $\mathrm{CD} 4^{+} \mathrm{CD} 25^{-} \mathrm{T}$ cells were further purified by cell sorting using a FACS ARIA II (Becton Dickinson, NJ, USA). For $\mathrm{T}$ helper cell cultures, dendritic cells were enriched by MACS purification using the CD11c microbeads (Miltenyi Biotec). Naive $\mathrm{CD}^{+}{ }^{+} \mathrm{T}$ cells were cocultured with dendritic cells at a 5:1 ratio, in the presence of $1 \mu \mathrm{g} / \mathrm{mL}$ anti-CD3, $10 \mu \mathrm{g} / \mathrm{mL}$ anti-IL-4, $10 \mu \mathrm{g} / \mathrm{mL}$ anti-IFN- $\gamma$ and the presence or absence of $10 \mathrm{nM}$ TSA, under polarizing conditions towards iTregs ( $5 \mathrm{ng} / \mathrm{mL}$ TGF- $\beta, 100 \mathrm{U} / \mathrm{mL}$ IL-2, and $10 \mathrm{nM}$ retinoic acid) or Th17 cells $(5 \mathrm{ng} / \mathrm{mL}$ TGF- $\beta, 10 \mathrm{ng} / \mathrm{mL}$ IL6 , and $10 \mathrm{ng} / \mathrm{mL} \mathrm{IL-1} \beta$ ) for 4 days. Before harvesting for chromatin immunoprecipitation (ChIP), naive $\mathrm{CD}^{+}$and iTreg cells were purified by cell sorting after surface staining with anti-CD4 and anti-CD25. Cell sorting was gated on the $\mathrm{CD} 4^{+} \mathrm{CD} 25^{-}$Foxp $^{-}$(naive) or $\mathrm{CD} 4^{+}$Foxp $3^{+}$population (iTregs). For Th17 sorting, cells were stained with anti-CD4 and permeabilized for further anti-IL-17A staining. Sorting was gated on the $\mathrm{CD} 4^{+} \mathrm{IL}_{17 \mathrm{~A}^{+}}$cells.

2.5. Isolation of Splenic DCs. Spleen tissue was fragmented and digested for $45 \mathrm{~min}$ at $37^{\circ} \mathrm{C}$ in the presence of collagenase $\mathrm{D}$ (Roche, Germany) and $2 \mu \mathrm{g} / \mathrm{mL}$ of DNAse I (Roche) in PBS plus $10 \%$ fetal bovine serum. Undigested fibrous material was removed by filtration through cell strainer. $\mathrm{CD}_{11 c^{+}}$ cells were obtained by positive selection using anti-CD11c microbeads (Miltenyi Biotec) according to the manufacturer's instructions.

2.6. Western Blot Analysis. Cells were washed twice with cold phosphate-buffered saline (PBS) and then lysed in RIPA buffer (50 mM Tris, $150 \mathrm{mM} \mathrm{NaCl}, 0.1 \%$ SDS, $0.5 \% \mathrm{Na}$ deoxycholate, and 1\% NP40) supplemented with a protease inhibitor cocktail. Protein concentration from lysates was determined by Bradford assay (Pierce, Rockford, IL, USA). Equal protein amount of cell lysates was loaded on the gels and subjected to SDS-PAGE. The separated proteins were transferred onto PVDF membranes and then analyzed by Western blotting using anti-H3 and anti-H3ac antibodies. Bands were quantified using Quantity One software (Bio$\mathrm{Rad})$.

2.7. ChIP and DNA Quantification. After cell sorting, cells were cross-linked with $1 \%$ formaldehyde for $10 \mathrm{~min}$. The reaction was quenched with $0.125 \mathrm{M}$ glycine for $5 \mathrm{~min}$, and cells were washed twice with PBS, resuspended in cell lysis buffer (10 mM Tris- $\mathrm{HCl} \mathrm{pH}$ 8.0, $10 \mathrm{mM} \mathrm{NaCl}, 0.2 \% \mathrm{NP}-40$, and a proteinase inhibitor cocktail) for $10 \mathrm{~min}$, and then resuspended in nuclear lysis buffer $(50 \mathrm{mM}$ Tris- $\mathrm{HCl} \mathrm{pH} 8.0$, $10 \mathrm{mM}$ EDTA, 1\% SDS, and a proteinase inhibitor cocktail). Lysate was sonicated with a Branson Sonifier 250, diluted twice in sonication buffer (50 mM HEPES pH 7.9, $140 \mathrm{mM}$ $\mathrm{NaCl}, 1 \mathrm{mM}$ EDTA, 1\% Triton X-100, 0.1\% deoxycholic acid, $0.1 \%$ SDS, and a proteinase inhibitor cocktail), and precleared with rabbit IgG and protein A agarose (Millipore). $3 \mathrm{ug}$ of the precleared samples was taken as input control and for ChIP reactions, which were performed overnight at $4^{\circ} \mathrm{C}$ with $1 \mathrm{ug}$ of anti-H3ac or $1 \mathrm{ug}$ of rabbit IgG. Immunocomplexes were isolated with protein A agarose and washed twice with the sonication buffer, once with wash buffer $(500 \mathrm{mM} \mathrm{LiCl}$, $100 \mathrm{mM}$ Tris $\mathrm{HCl} \mathrm{pH} 8.0,1 \%$ NP-40, and $0.1 \%$ deoxycholic acid), and once with TE (50 mM Tris-HCl pH 8.0 and 2 mM EDTA). Samples were then eluted with $100 \mathrm{uL}$ of the immunoprecipitation elution buffer $(50 \mathrm{mM} \mathrm{NaHCO}$ and $1 \%$ SDS), and finally the cross-link was reversed by incubating the samples at $65^{\circ} \mathrm{C}$ in $200 \mathrm{mM} \mathrm{NaCl}$. Samples were treated with $1 \mathrm{mg} / \mathrm{mL}$ proteinase $\mathrm{K}$ and the DNA isolated by DNA Clean and Concentrator kit (Zymo Research). For quantification of the immunoprecipitated DNA, KAPA SYBR FAST (KAPA Biosystems) was used according to the manufacturer's 
instructions. Immunoprecipitated DNA was quantified by creating a line of best fit from a standard curve using serial dilutions of genomic template DNA to allow normalization of primer sets. Primers for the foxp 3 promoter were as follows: forward, $5^{\prime}$ CCTTGGCAACATGATGGTGGTGAT $3^{\prime}$; reverse, $5^{\prime}$ AAGAAGGGATCAGAAGCCTGCCAT $3^{\prime}$.

2.8. Analysis of Treg Cell Function. For Treg suppression assays, carboxyfluorescein-succinimidyl-ester- (CFSE-, Invitrogen) labeled effector $\mathrm{T}$ cells $\left(\mathrm{CD} 4^{+} \mathrm{CD} 25^{-}\right)$were stimulated with $1 \mathrm{mg} / \mathrm{mL}$ of antibody against $\mathrm{CD} 3 \varepsilon$ (eBioscience) in the presence of $\mathrm{CD}_{11} \mathrm{c}^{+}$dendritic cells at a ratio of $1: 2$ ( $\mathrm{T}$ effector: dendritic cells) and at a ratio of $1: 0.5$ of $\mathrm{T}$ effector: purified $\mathrm{CD} 4^{+} \mathrm{Foxp}^{+}$Treg cells generated with or without TSA. To rule out that TSA acted upon dendritic cells rather than on the $\mathrm{T}$ lymphocytes, suppression assays were performed after activating the T cells in the presence of platebound anti-CD3 $(0.5 \mu \mathrm{g} / \mathrm{mL}$ and $5 \mu \mathrm{g} / \mathrm{mL})$ and soluble antiCD28 $(1 \mu \mathrm{g} / \mathrm{mL})$ and in the absence of dendritic cells. After 72 hours, suppression of proliferation was determined by flow cytometry analysis of CFSE dilution using a FACS Canto II cytometer (BD), and data were analyzed using FACS Diva software (BD).

\section{Results}

3.1. The foxp3 Promoter Is Hyperacetylated on iTreg Cells. We first sought to analyze the patterns of histone $\mathrm{H} 3$ acetylation on differentiated Treg cells. For this purpose, we cultured naive $\left(\mathrm{CD} 4^{+} \mathrm{CD} 25^{-}\right.$Foxp $\left.3^{-}\right)$T cells with spleenderived $\mathrm{CD}_{11 \mathrm{c}^{+}}$DC plus $\alpha$-CD3 mAb under Treg polarizing conditions for 4 days and then cells were sorted to purify the resulting Treg population $\left(\mathrm{CD} 4^{+} \mathrm{CD} 25^{+} \mathrm{Foxp}^{+}\right)$ (Figure 1(a)). We then analyzed by ChIP assay the H3ac mark on the histone $\mathrm{H} 3$ of the foxp 3 promoter on both, the sorted naive $\mathrm{CD} 4^{+} \mathrm{T}$ cells and the in vitro iTreg (Figure $1(\mathrm{~b})$ ). The results show that when compared to the naive $\mathrm{CD}^{+}{ }^{+} \mathrm{T}$ cells, histone $\mathrm{H} 3$ is hyperacetylated at the foxp 3 promoter in iTreg cells. To demonstrate that the acetylation of the foxp3 promoter was related to the differentiation of naive $\mathrm{CD} 4^{+} \mathrm{T}$ lymphocytes to Treg cells, we also compared the level of $\mathrm{H} 3 \mathrm{ac}$ of the foxp 3 promoter on in vitro differentiated naive $\mathrm{CD}^{+}{ }^{+} \mathrm{T}$ cells to Th17 cells (Figure $1(\mathrm{a})$ ). As expected, the acetylation levels of the foxp 3 promoter did not change on differentiated Thl7 cells. Thus, we conclude that the foxp 3 promoter becomes hyperacetylated on histone $\mathrm{H} 3$ upon differentiation of naive $\mathrm{CD} 4^{+} \mathrm{T}$ cells to Treg cells.

3.2. TSA Increases the Generation of Treg In Vitro. Since the acetylation patterns of histone $\mathrm{H} 3$ changes during Treg differentiation, we next questioned whether by affecting the acetylation levels of histone $\mathrm{H} 3$, Treg differentiation could be pharmacologically modulated. For this purpose, we cultured naive $\left(\mathrm{CD} 4^{+} \mathrm{CD} 25^{-}\right.$Foxp $\left.3^{-}\right) \mathrm{T}$ cells with spleenderived $\mathrm{CD}_{11 c^{+}}$dendritic cells plus $\alpha$-CD3 mAb under iTreg polarizing conditions in the presence or absence of the histone deacetylase inhibitor TSA. After 4 days, Foxp3-GFP expression was assessed by FACS, as an indicator of Treg differentiation. Figure 2(a) shows that $69 \%$ of the population expressed Foxp3, whereas the percentage increased to $78 \%$ when naive T cells were differentiated in the presence of TSA. Statistical analyses on 6 independent experiments indicated that the TSA treatment increased the differentiation of Tregs by $14.8 \%$ compared to untreated cultures (Figure 2(b)). To confirm that the mechanism involved in the effect of TSA on Treg differentiation implied changes on the acetylation levels of histone $\mathrm{H} 3$, we isolated total protein extracts from iTreg and analyzed the acetylation levels of histone H3. Western blot analyses showed that TSA treatment increased the global levels of acetylated histone $\mathrm{H} 3$ on Tregs by nearly two fold compared to untreated cultures (Figures 2(c) and 2(d)). Taken together, these results suggest that TSA stimulates the differentiation of Tregs while at the same time increasing the levels of histone $\mathrm{H} 3$ acetylation.

3.3. TSA Upregulates Treg Suppressive Capacity. Next we tested the activity of the Tregs generated in the presence of TSA. For this, $\mathrm{CD}^{+}{ }^{+} \mathrm{Foxp}^{+}{ }^{+}$Treg cells were generated as indicated above and after 4 days of culture the resultant Foxp $3^{+} \mathrm{CD}^{+}$population was cocultured with CFSE-labeled naive $\mathrm{T}$ cells in the presence of $\mathrm{CD} 11 \mathrm{c}^{+} \mathrm{DCs}$ and anti-CD3, in a conventional $\mathrm{T}$ cell suppression assay. Figure 3 shows that at a ratio of 1 effector to $0.5 \mathrm{Treg}$, the proliferation of the naive T lymphocytes was clearly suppressed by the Treg. Interestingly, Treg generated in the presence of TSA showed a higher suppressive activity compared to those generated in the absence of the drug. Therefore, these results show that TSA increased the ability of Tregs to suppress the in vitro proliferation of CFSE-labeled naive $\mathrm{CD} 4^{+} \mathrm{T}$ cells. To determine if the effect of TSA on the activity of Tregs was due to a direct effect of the drug on Treg cells, Tregs were generated in the absence of dendritic cells by activating naive $\mathrm{T}$ cells with plate-bound anti-CD3 and soluble anti-CD28. The results show that TSA increases the suppressive activity of Tregs even when generated in the absence of dendritic cells (Figures 3(a) and 3(b)). However, Tregs generated in the presence of dendritic cells show higher suppressive activity than those generated using activating antibodies. Moreover, the number of Tregs generated in the presence of dendritic cells needed to achieve 50\% suppression is half of those generated in the presence of activating antibodies (ratio 1:0.5 in the presence of dendritic cells versus 1:1 in the presence of activating antibodies).

\subsection{Tregs Generated under TSA Treatment Differentially} Express Treg Markers Involved in Their Suppressive Functions. Besides Foxp3 and IL-10 secretion, several additional markers such as CTLA-4 (cytotoxic T-lymphocyte associated molecule-4), GITR (glucocorticoid-induced TNF receptor), and LAG-3 are also expressed on regulatory T cells; however the functional significance of these molecules remains to be defined. Also the ectonucleotidases CD39 and CD73 are expressed in Treg and convert ATP into immunosuppressive adenosine. As TSA increased the differentiation and suppressive functions of Treg cells, we decided to analyze whether TSA was capable of inducing changes in the expression of 

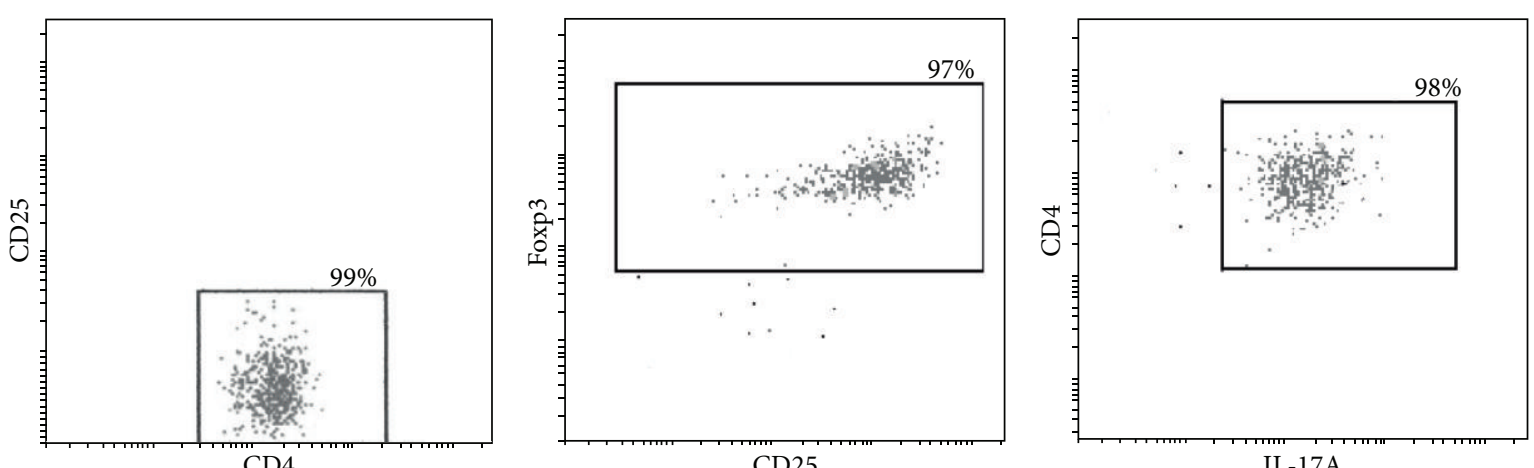

(a)

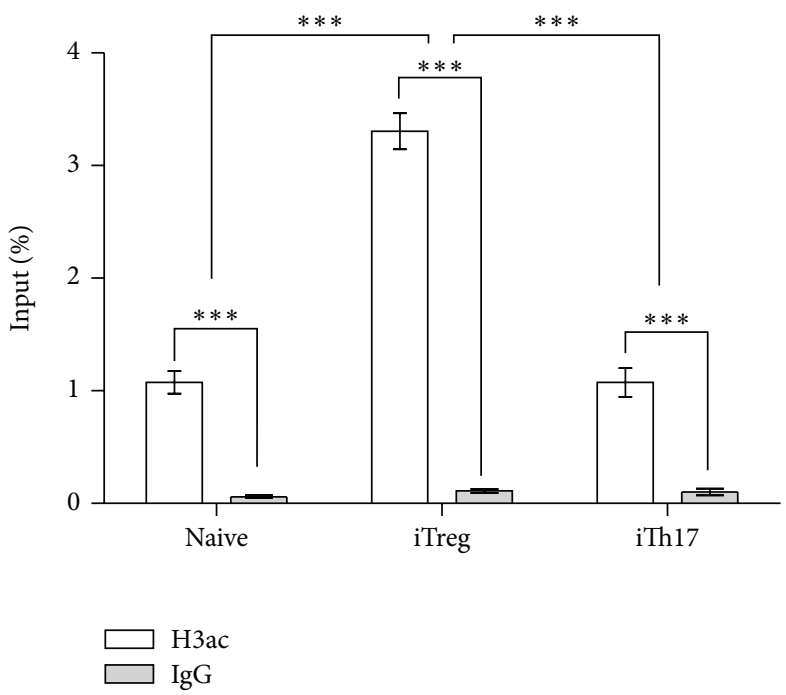

(b)

FIGURE 1: The foxp3 promoter is hyperacetylated on iTreg cells. (a) Flow cytometry of the sorted naive cells and in vitro differentiated Treg and Th17 cells. Numbers indicate the percentage of naive $\left(\mathrm{CD} 4^{+} \mathrm{CD} 25^{-}\right)$, Treg $\left(\mathrm{CD} 4^{+}\right.$Foxp $\left.3^{+}\right)$, and Th17 $\left(\mathrm{CD} 4^{+} \mathrm{IL}-17^{+}\right)$positive cells. (b) chromatin immunoprecipitation assays on foxp 3 promoter. ChIP assays were performed on sorted splenic naive CD $4^{+} \mathrm{T}$ cells and in vitro induced Tregs and Th17 cells. DNA fragments bound to acetylated histones were immunoprecipitated using antibodies directed against acetylated histone H3 (H3ac) or a rabbit isotype-matched immunoglobulin G (IgG), as control. Precipitated DNA was quantified by real-time PCR with primers specific for the foxp 3 gene promoter, and the PCR products were set in relation to input DNA. Standard deviation was obtained from three (naive and iTregs) and two (iTh17) independent experiments.

these additional Treg markers. For this purpose, we generated Tregs in the presence or absence of TSA for 4 days as described, and we then stained the cells with specific antibodies. Figure 4 shows that although no significant changes could be detected in the expression of CTLA- 4 or GARP, the mean fluorescence of TSA-treated Treg for the ectonucleotidases CD39 and CD73 showed significant increase of 1.7- and 1.4 -fold, respectively. We also observed a modest (0.5-fold) decrease in the mean fluorescence of LAG-3. These results indicate that TSA may affect the immune suppressive activity of Treg by specifically increasing the protein levels of the ectonucleotidases CD39 and CD73, the expression of which is driven by Foxp3, the Treg-specific transcription factor. This result may be a clue to the mode of action of TSA on Treg activity. When analyzing IL-10 secretion, we found no differences in Tregs generated in the presence or absence of TSA, when these Tregs were generated in the absence of dendritic cells. However, we found that TSA produced higher IL-10 secretion ( 2.5 fold) when Tregs were produced in the presence of DCs, probably due to an effect of TSA on DCs rather than on the Tregs.

\section{Discussion}

It is well known that histone posttranslational modifications play an important role in the regulation of gene expression and that pharmacological control of histone-modifying enzymes could be potentially used to manipulate the differentiation of specific cellular lineages. On the other hand, defects in the development or function of regulatory $\mathrm{T}$ cells contribute significantly to the pathogenesis of many inflammatory and autoimmune diseases. Thus, there are important 

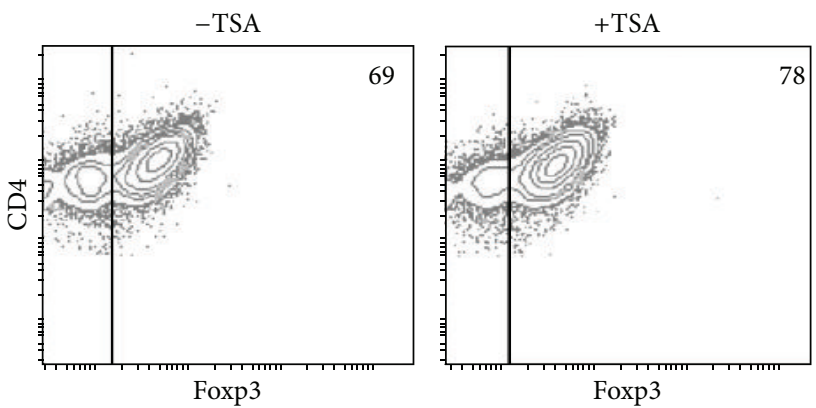

(a)

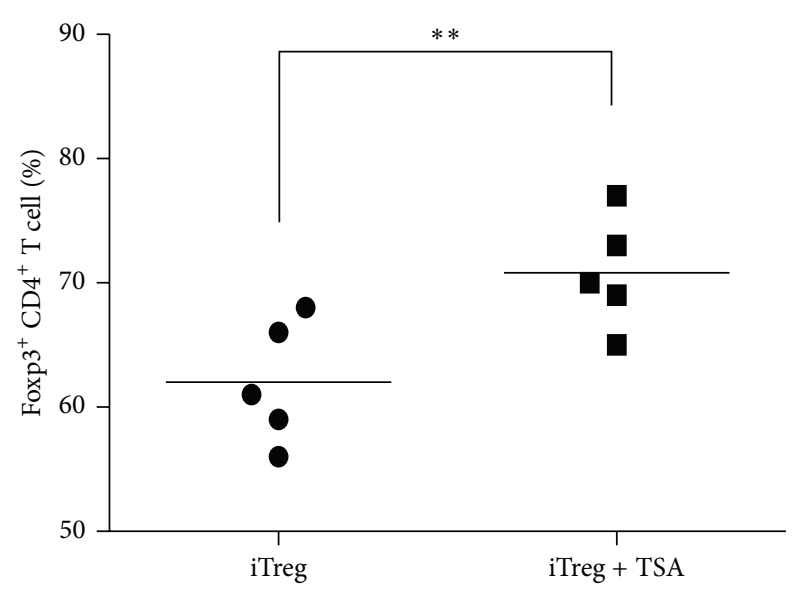

(b)

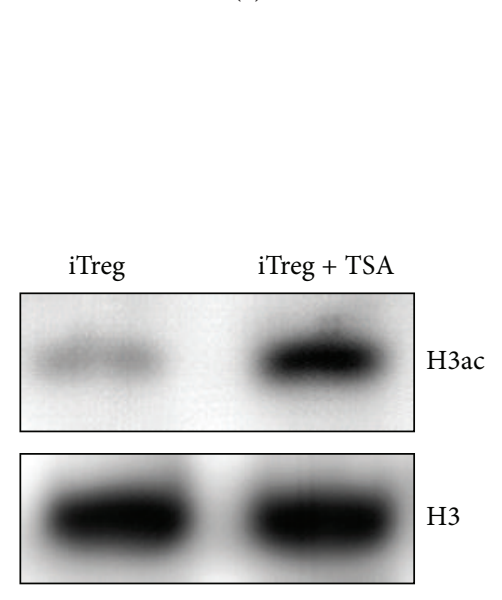

(c)

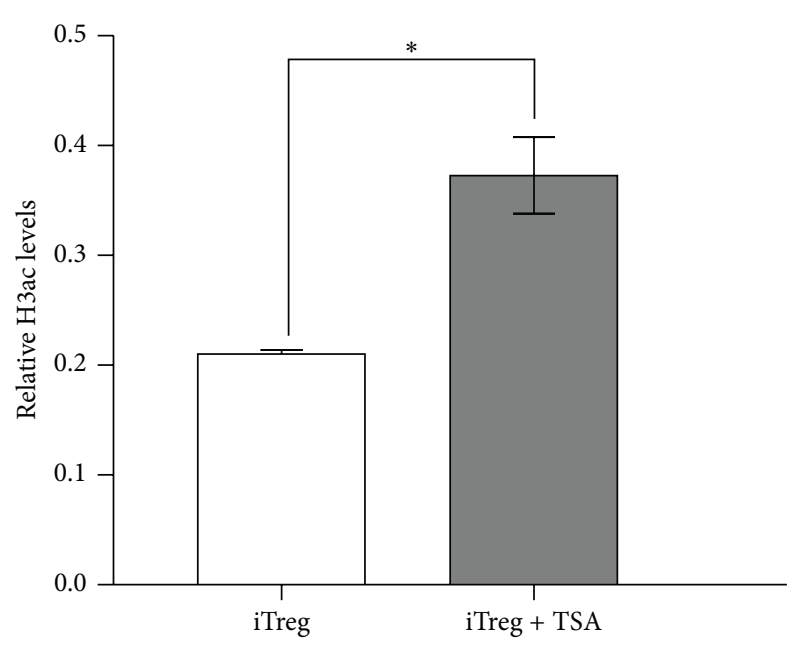

(d)

Figure 2: TSA increases the generation of Tregs from naive CD $4^{+} \mathrm{T}$ cells. (a) Flow cytometry analysis of $\mathrm{CD} 4^{+}$Foxp $3^{+}$cells generated in the absence (left) or presence (right) of $10 \mathrm{nM}$ TSA for 4 days. Numbers indicate the percentage of $\mathrm{CD} 4^{+}$Foxp $3^{+}$double positive cells. (b) Scatter plot depicts percentage of $\mathrm{CD} 4^{+} \mathrm{Foxp}^{+}$double positive cells from five independent experiments in the presence and absence of TSA. ${ }^{* *} P<0.008$ by student's $t$-tests. (c) Western blot analyses of total protein extracts derived from Tregs differentiated in the absence or presence of $10 \mathrm{nM}$ TSA, as indicated. (d) Quantitation of the acetylation levels relative to the histone H3 with the Quantity One software. Standard deviation was obtained from three independent experiments. ${ }^{*} P<0.05$ by two-way ANOVA.

attempts to develop new strategies for generating Foxp $3^{+}$ regulatory $\mathrm{T}$ cells as a valuable therapy for these diseases. HDAC inhibitors have previously shown to induce cell-cycle arrest and apoptosis in cancer and $\mathrm{CD}^{+} \mathrm{T}$ cells $[15,16]$ and to have anti-inflammatory effects on human monocytes [17]. Specifically, the histone deacetylase inhibitor TSA has been shown to modulate inflammatory and immune responses by boosting thymic production of naturally occurring Treg cells and also to increase the suppressive function of Treg in vivo [13].

In this study, we analyzed the effect of TSA on the differentiation of naive $\mathrm{CD}^{+} \mathrm{T}$ cells towards a regulatory phenotype and performed a functional and phenotypic characterization of TSA-differentiated Tregs. We observed that TSA stimulates the differentiation of naive $T$ cells towards a Treg phenotype and that this stimulation correlated with hyperacetylation of the global histone H3. This suggests that TSA may act through the hyperacetylation of the histone $\mathrm{H} 3$ in the foxp 3 promoter. Interestingly, it has been reported that the Foxp 3 protein becomes acetylated as well, preventing its proteasomal degradation [18]. Thus, the increased $\mathrm{CD} 4^{+} \mathrm{Foxp}^{+} \mathrm{T}$ cell population produced by TSA could possibly be the result of combined pathways: by the upregulation of the foxp 3 gene expression mediated by the hyperacetylation of the histone $\mathrm{H} 3$ on the foxp 3 promoter and, on the other hand, by increasing the Foxp3 protein's halflife. The stimulation of Treg differentiation that we observed by TSA could explain, at least in part, the anti-inflammatory effect of TSA. This could be due to an increase in peripheral Treg cells generation, as it has been suggested by Tao et al. [13].

Since our differentiation experiments were carried out in the presence of $\mathrm{CD}_{11 c^{+}}$dendritic cells we wanted to rule out that TSA affected the DC and thus indirectly Treg activity. 


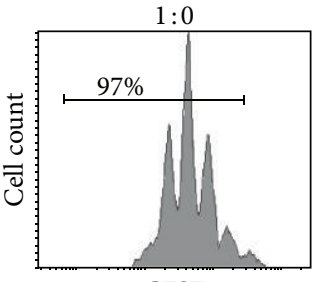

CFSE
Treg $(\alpha \mathrm{CD} 3+\mathrm{DCs})$

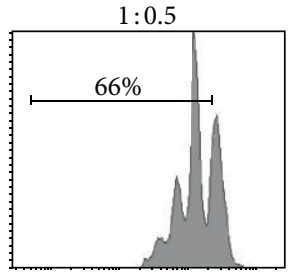

CFSE

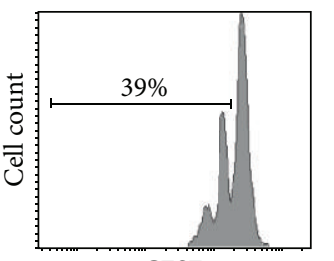

CFSE

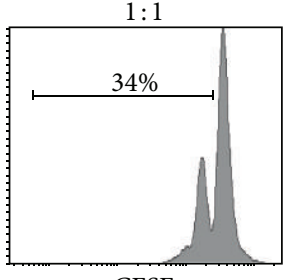

CFSE

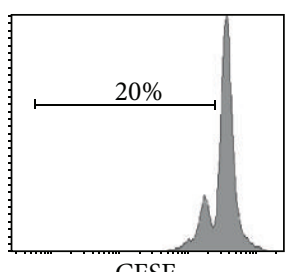

CFSE

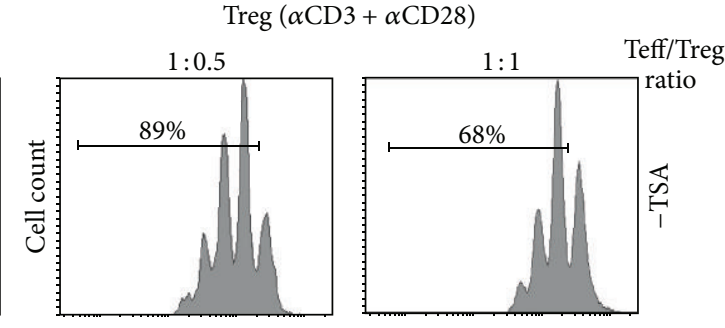

CFSE

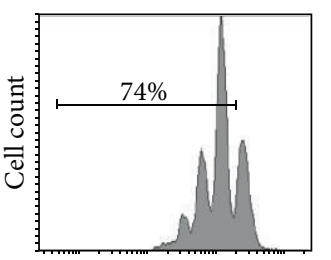

CFSE
CFSE

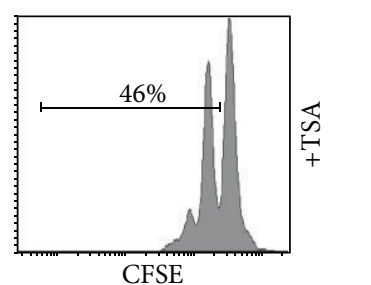

(a)
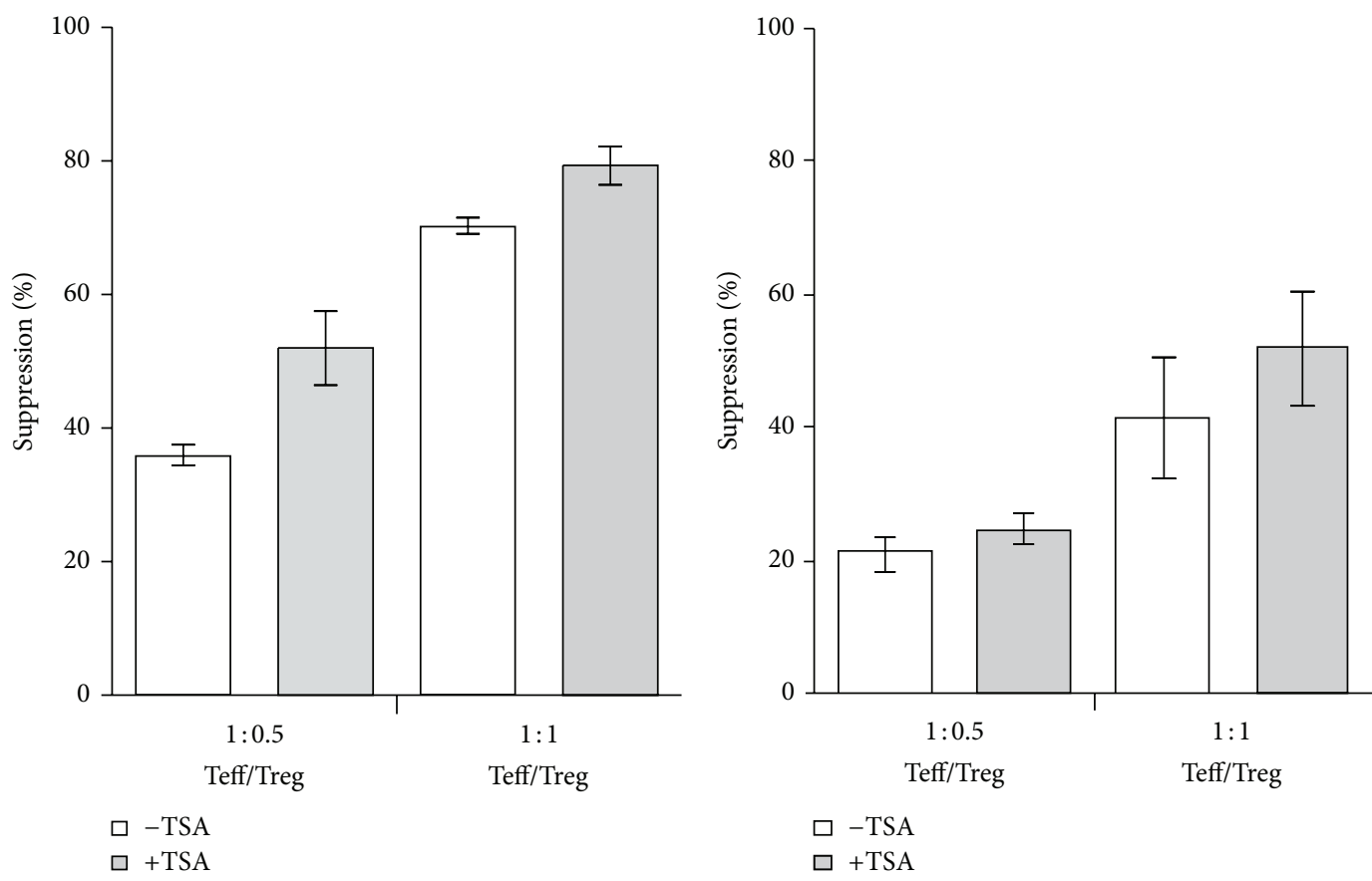

(b)

FIgURE 3: TSA Treg presents higher suppressive capacity. (a) Treg suppression assays of Tregs generated in the presence (left) or absence (right) of dendritic cells, and with (+TSA) or without TSA (-TSA). Tregs from each group were added to CFSE-labeled naive CD4 ${ }^{+}$T cells cocultivated with dendritic cells plus anti-CD3 antibody. The percentage of proliferating T cells is shown in each plot. Data are representative of three independent experiments. (b) Quantitation of the percentage of suppression of Tregs generated with or without TSA in the presence of anti-CD3 and dendritic cells (left) or plate-bound anti-CD3 and soluble anti-CD28 (right).

Our results show that Tregs generated in the absence of DC but in the presence of activating antibodies also show an increased suppressive activity, indicating that TSA acts on naive $\mathrm{T}$ cells. However the results also suggest that dendritic cells may become more tolerogenic in the presence of TSA, since the number of Tregs generated in the presence of TSA and dendritic cells needed to achieve $50 \%$ suppression is half of those generated in the presence of activating antibodies (ratio 1:0.5 in the presence of dendritic cells versus 1:1 in the presence of activating antibodies). Consistently, it has been reported that TSA can change dendritic cells into a tolerogenic phenotype in vitro [19], so the evidence points to the fact that both Tregs and dendritic cells are targets for TSA.

Importantly, we also demonstrated that TSA increases Treg functions. Tregs exert their functions in several ways. The widely recognized mechanisms of suppression include the secretion of suppressive soluble factors, cell contactmediated suppression, and competition for growth factors. 

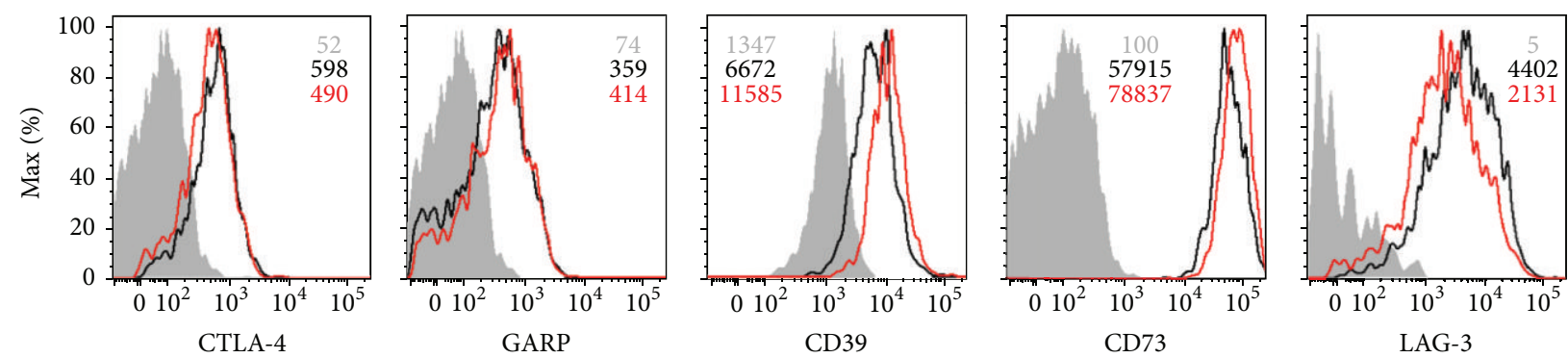

(a)

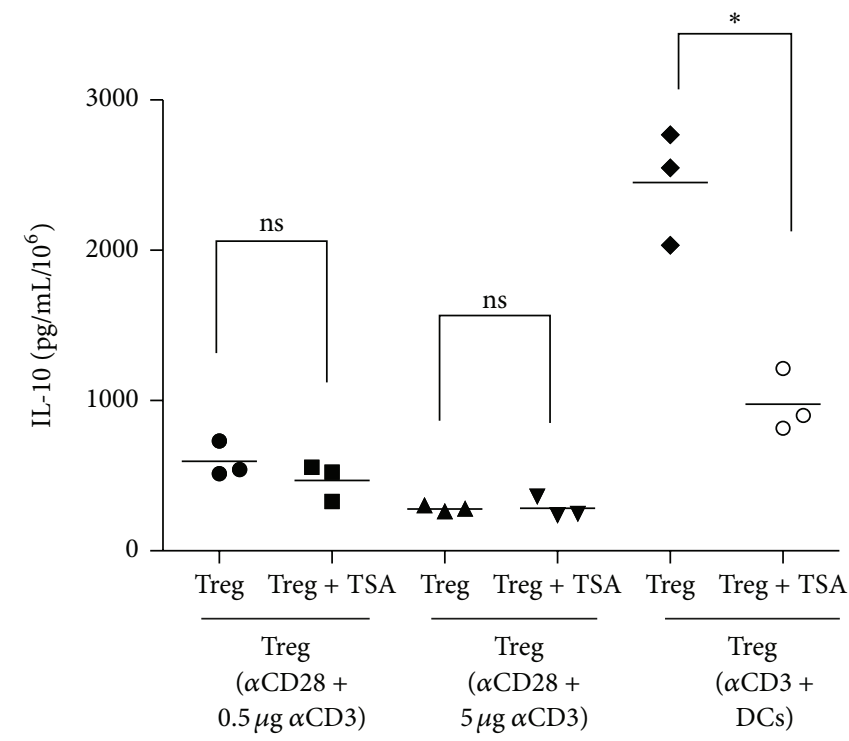

(b)

FIGURE 4: Phenotypical characterization of Tregs generated under TSA treatment. (a) Representative histograms of CTLA-4, GARP, CD39, CD73, and LAG-3 expression on Tregs generated in the absence (black) or presence (red) of TSA. Controls are filled histograms. Average MFI \pm SEM was derived from three independent experiments. (b) IL-10 secretion was determined using the CBA method. Each point represents an individual mouse.

The phenotypic characterization of Tregs generated in the presence or absence of TSA gave us some lights on the mechanisms by which TSA could be affecting Treg suppressive functions. We found that TSA increased the expression of CD39 and CD73 ectonucleotidases in Tregs. These ectoenzymes generate pericellular adenosine from extracellular nucleotides that suppress effector $\mathrm{T}$ cell functions [20]. The correlation between the TSA effect and the level of these ectoenzymes could explain the higher suppressive activity observed in Treg cells generated under the TSA treatment. In contrast, TSA decreased the expression of LAG-3, a molecule involved in Treg cell suppression of dendritic cell function [21], suggesting that the expression of CD39 and CD73 might compensate this reduction. On the other hand, no differences in the expression of GARP or CTLA- 4 were observed between both types of Treg cells. Although we found that TSA could increase the production of IL-10, these effects could only be seen in the condition where Tregs were generated in the presence of dendritic cells, so it could be due to an effect on them. Further work needs to be performed to better understand the Treg cells suppressor mechanisms being affected by TSA. A better understanding of the effect of TSA on Treg cells should provide important tools to therapeutically enhance Treg production and suppressive function. In conclusion, our results showed that the outcome of pharmacological modulation of histonemodifying enzymes on the differentiation of Tregs might be exploited as potential valuable therapy for autoimmune diseases.

\section{Authors' Contribution}

Cristian Doñas and Macarena Fritz contributed equally to this work.

\section{Acknowledgments}

The authors thank Paz Reyes for technical help with cell sorting and flow cytometry and Sebastián Valenzuela for valuable veterinary assistance at the Fundación Ciencia \& Vida animal facility. This research was supported by the 
Grants PBF-16 (MR); Fondecyt Grants 1100448 (MR), 1120170

(AL), and 1100557 (MRB); and DI-68-1211 (MF).

\section{References}

[1] R. Khattri, T. Cox, S. A. Yasayko, and F. Ramsdell, "An essential role for Scurfin in $\mathrm{CD} 4{ }^{+} \mathrm{CD} 25^{+} \mathrm{T}$ regulatory cells," Nature Immunology, vol. 4, no. 4, pp. 337-342, 2003.

[2] J. D. Fontenot, M. A. Gavin, and A. Y. Rudensky, "Foxp3 programs the development and function of $\mathrm{CD} 4{ }^{+} \mathrm{CD} 25^{+}$regulatory T cells," Nature Immunology, vol. 4, no. 4, pp. 330-336, 2003.

[3] J. H. Buckner and S. F. Ziegler, "Functional analysis of FOXP3," Annals of the New York Academy of Sciences, vol. 1143, pp. 151169,2008

[4] C. Dejaco, C. Duftner, B. Grubeck-Loebenstein, and M. Schirmer, "Imbalance of regulatory T cells in human autoimmune diseases," Immunology, vol. 117, no. 3, pp. 289-300, 2006.

[5] B. M. Javierre, H. Hernando, and E. Ballestar, "Environmental triggers and epigenetic deregulation in autoimmune disease," Discovery Medicine, vol. 12, no. 67, pp. 535-545, 2011.

[6] A. C. Jenke and M. Zilbauer, "Epigenetics in inflammatory bowel disease," Current Opinion in Gastroenterology, vol. 28, no. 6, pp. 577-584, 2012.

[7] T. Kouzarides, "Chromatin modifications and their function," Cell, vol. 128, no. 4, pp. 693-705, 2007.

[8] Z. Liu, A. Mai, and J. Sun, "Lysine acetylation regulates Bruton's tyrosine kinase in B cell activation," Journal of Immunology, vol. 184, no. 1, pp. 244-254, 2010.

[9] R. W. Johnstone, "Histone-deacetylase inhibitors: novel drugs for the treatment of cancer," Nature Reviews Drug Discovery, vol. 1, no. 4, pp. 287-299, 2002.

[10] T. A. McKinsey and E. N. Olson, "Cardiac histone acetylationtherapeutic opportunities abound," Trends in Genetics, vol. 20, no. 4, pp. 206-213, 2004.

[11] M. A. Glozak, N. Sengupta, X. Zhang, and E. Seto, "Acetylation and deacetylation of non-histone proteins," Gene, vol. 363, no. 1-2, pp. 15-23, 2005.

[12] H. J. Kim and S. C. Bae, "Histone deacetylase inhibitors: molecular mechanisms of action and clinical trials as anticancer drugs," The American Journal of Translational Research, vol. 3, no. 2, pp. 166-179, 2011.

[13] R. Tao, E. F. de Zoeten, E. Ozkaynak et al., "Deacetylase inhibition promotes the generation and function of regulatory T cells," Nature Medicine, vol. 13, no. 11, pp. 1299-1307, 2007.

[14] N. Mishra, C. M. Reilly, D. R. Brown, P. Ruiz, and G. S. Gilkeson, "Histone deacetylase inhibitors modulate renal disease in the MRL-lpr/lpr mouse," Journal of Clinical Investigation, vol. 111, no. 4, pp. 539-552, 2003.

[15] J. M. A. Moreira, P. Scheipers, and P. Sørensen, "The histone deacetylase inhibitor Trichostatin A modulates $\mathrm{CD}^{+} \mathrm{T}$ cell responses," BMC Cancer, vol. 3, article 30, 2003.

[16] S. Minucci and P. G. Pelicci, "Histone deacetylase inhibitors and the promise of epigenetic (and more) treatments for cancer," Nature Reviews Cancer, vol. 6, no. 1, pp. 38-51, 2006.

[17] M. D. Säemann, G. A. Böhmig, C. H. Osterreicher et al., "Antiinflammatory effects of sodium butyrate on human monocytes: potent inhibition of IL-12 and up-regulation of IL-10 production," The FASEB Journal, vol. 14, no. 15, pp. 2380-2382, 2000.

[18] J. van Loosdregt, Y. Vercoulen, T. Guichelaar et al., "Regulation of Treg functionality by acetylation-mediated Foxp3 protein stabilization," Blood, vol. 115, no. 5, pp. 965-974, 2010.
[19] K. Misaki, A. Morinobu, J. Saegusa et al., "Histone deacetylase inhibition alters dendritic cells to assume a tolerogenic phenotype and ameliorates arthritis in SKG mice," Arthritis Research and Therapy, vol. 13, no. 3, article R77, 2011.

[20] S. Deaglio, K. M. Dwyer, W. Gao et al., "Adenosine generation catalyzed by CD39 and CD73 expressed on regulatory T cells mediates immune suppression," Journal of Experimental Medicine, vol. 204, no. 6, pp. 1257-1265, 2007.

[21] C. T. Huang, C. J. Workman, D. Flies et al., "Role of LAG-3 in regulatory T cells," Immunity, vol. 21, no. 4, pp. 503-513, 2004. 


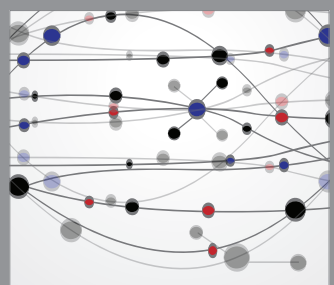

The Scientific World Journal
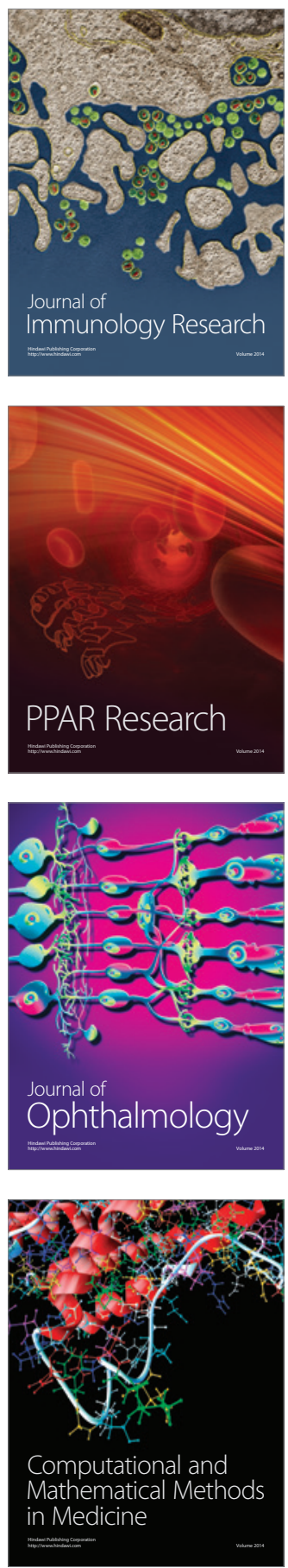

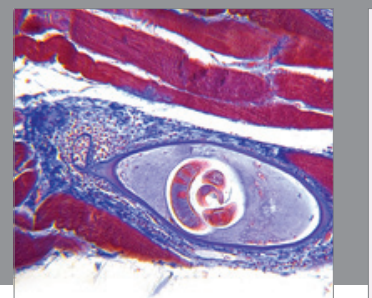

Gastroenterology

Research and Practice
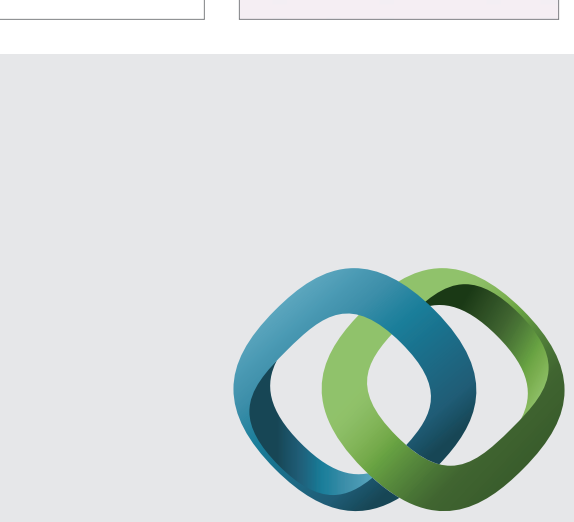

\section{Hindawi}

Submit your manuscripts at

http://www.hindawi.com
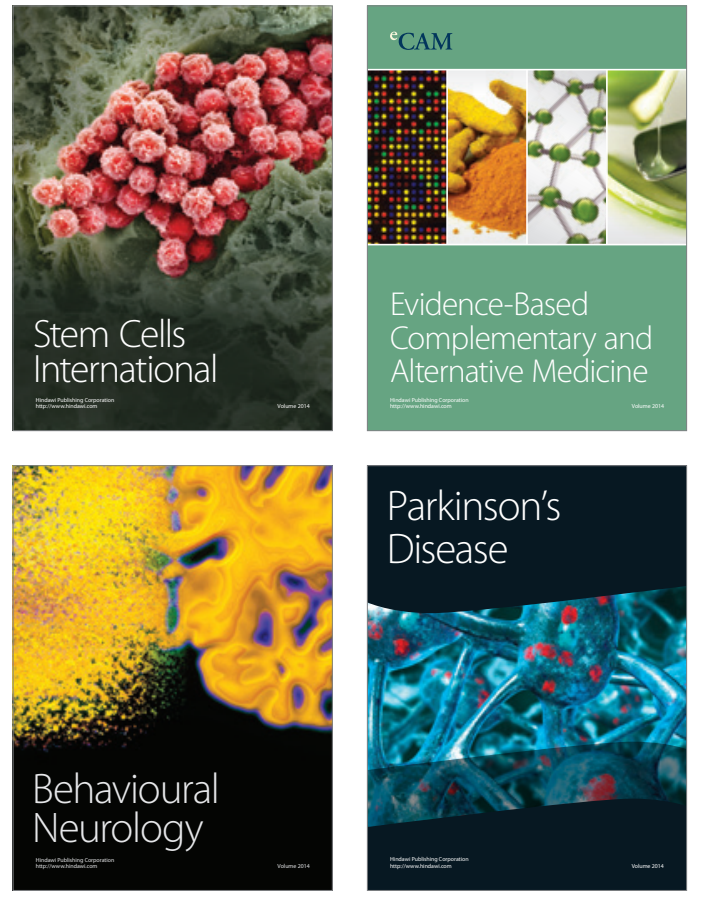
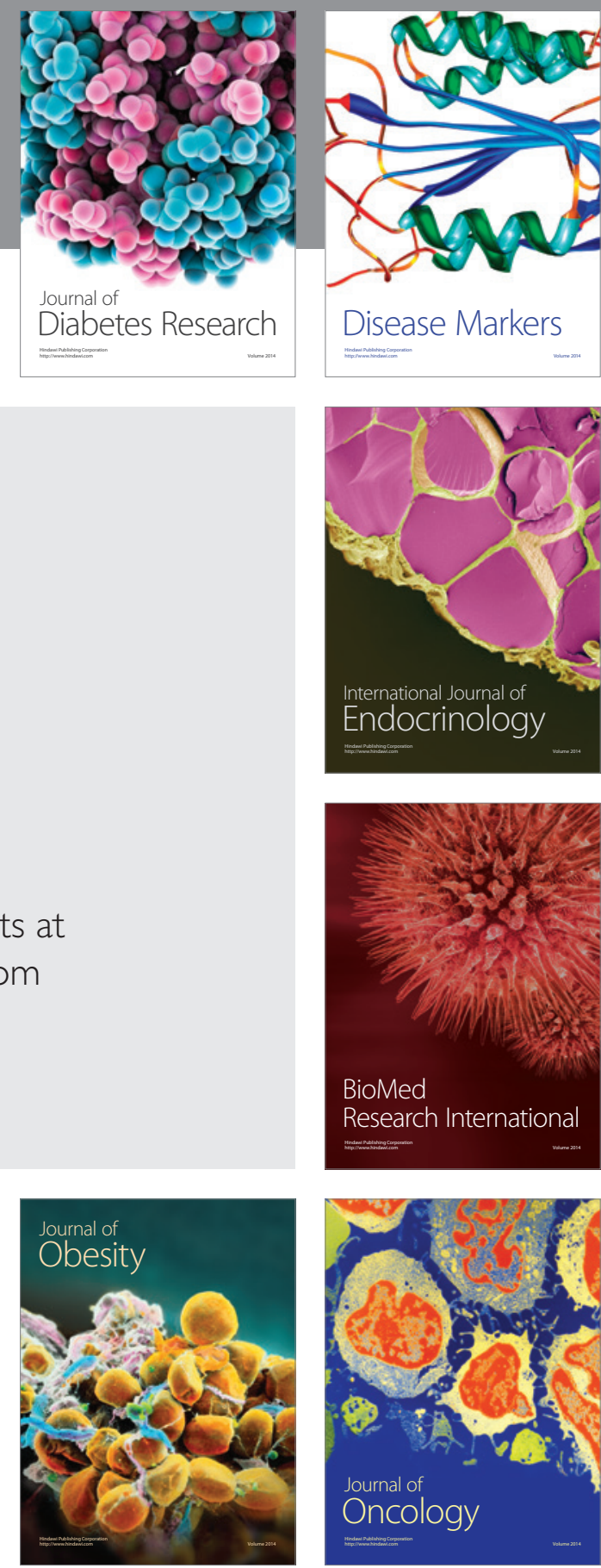

Disease Markers
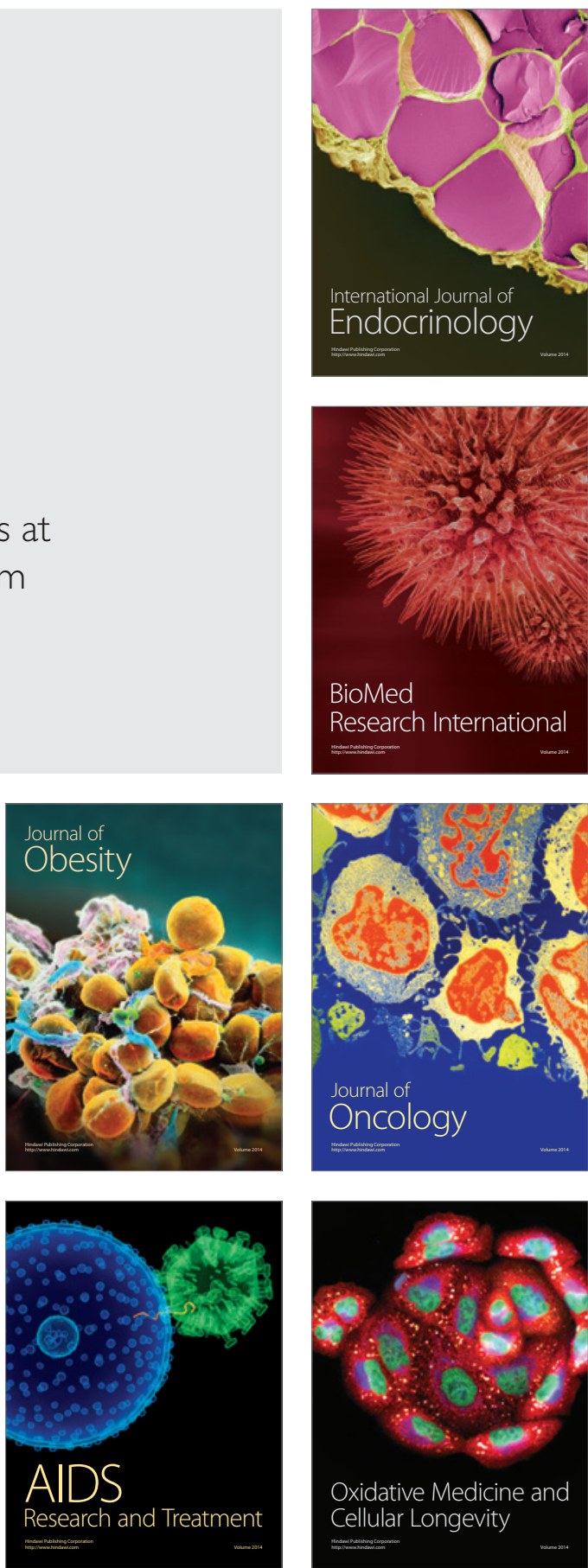